\title{
The knowledge and attitude of father in breastfeeding: a questionnaire- based study
}

\author{
Santosh S. ${ }^{1}$, Geetha $\mathbf{M}^{2}$, Kiran $B^{3}$ \\ ${ }^{1}$ Dr. Santosh Srinivasiah, ${ }^{2}$ Dr. Geetha M., ${ }^{3}$ Dr. Kiran B, East Point College of Medical Sciences and Research Centre, \\ Bangalore, Karnataka, India.
}

Corresponding Author: Dr. Geetha M, East Point College of Medical Sciences and Research Centre, Bangalore, Karnataka, India. E-mail: gee_festoon@yahoo.co.in

\begin{abstract}
Introduction: The father's support is most fundamental influence in the breastfeeding process, but attitude and knowledge of men towards breastfeeding has not been given due importance and been rarely explored and studied. Aim: This study aims at evaluating the knowledge and attitude of fathers of neonates about breastfeeding. Materials and methods: Using questionnaire approach a prospective cohort study was undertaken over a period of three months from April 2019 to June 2019 in our medical college hospital. Fathers of 104 neonates born consecutively in our tertiary care centre have been included in the study. Results: A total of 104 fathers were included in the study ( $\mathrm{n}=104)$. The average of the fathers interviewed was 28.8 years. Most were literate, having completed high school. All fathers agreed that breast feeding is essential. Only $40 \%$ felt exclusive breastfeeding to be given. 92 out of 104 (90\%) agreed breast feeding is a cheaper option than formula feeds. Surprisingly, only 12 out of $104(11 \%)$ reported any difficulty in breast feeding. Only about $30 \%$ had attended antenatal counselling regarding breast feeding though nearly $70 \%$ felt fathers have a supporting role in breast feeding. Less than 10\% father's felt they have no role in breast feeding. Conclusion: We conclude that attitude of father plays a major role in making breastfeeding exclusive. Hence knowledge of breastfeeding should be given to fathers as well in antenatal period.
\end{abstract}

Keywords: Father, Breastfeeding, Knowledge, Attitude, Infant formula feeds

\section{Introduction}

Breastfeeding is important to both child and maternal health \& wellbeing. Breast milk is essential for somatic growth, modulation of gastrointestinal function, immune ontogeny, brain development, protective against obesity and type 2 diabetes. [1] For the mother, breast feeding suggests to be onco protective, from breast and ovarian malignancy. It also seems have a protective effect from type 2 diabetes and obesity.

Breast feeding improves bonding with the child and spouse and may help to reduce and prevent depression [2]. The role of breastfeeding in causing lactational amenorrhoea and its advantages to the mother specially in natural contraception and birth spacing is well known. Breast milk is the ideal nutrient for the healthy growth \& development of infants. World health organisation (WHO) recommends that babies be

Manuscript received: $26^{\text {th }}$ August 2019

Reviewed: $4^{\text {th }}$ September 2019

Author Corrected: $10^{\text {th }}$ September 2019

Accepted for Publication: 17 $7^{\text {th }}$ September 2019 exclusively breastfed till six months of age [3]. Mother's own milk is the best source of nutrition. In addition to its nutritional advantage, breastfeeding is convenient and inexpensive, and also is a bonding experience for the mother and infant [1]. The American Academy of Paediatrics, Indian academy of paediatrics, Academy of Nutrition and Dietetics all support and endorse this recommendation [2].

Literature reaffirms the protective effect of exclusive breastfeeding during the first six months of life against infectious diseases, with an $88 \%$ reduction of mortality. [2]. Further breast feeding is to be continued till age of 2 years along with weaning diet. [3] However, even among mothers from advantaged backgrounds, these recommendations are hardly fulfilled.

Globally, only $38 \%$ of infants are exclusively breastfed [1]. The general consensus finding is that infant feeding practices are incongruent with the guidelines [4].

Pediatric Review: International Journal of Pediatric Research Available online at: www.medresearch.in 454|P a g e 


\section{Original Research Article}

Numerous studies suggest that breast feeding initiation, exclusivity, support, continuation and cessation are all strongly influenced by the father $[5,6]$. In pediatric nutrition significant gap between practices and current guidelines is notable only for breast-feeding and use of formula.

Parents do not follow medical professional advice often. The main reason for not adhering to the advice was that they did not consider it suitable for their infant and they preferred to rely on their feelings or recommendations from familiars [3]. The attitude of fathers has been shown to be the important determinants of infant feeding but it is rarely explored.

The participation and the support by father are essential and major predicting factor for interruption of breast feeding $[5,7]$.

The fathers are rarely included in antenatal counselling about breastfeeding. The active involvement and support of father in breastfeeding will help in efficient practice of breastfeeding $[6,8]$. The present study aims at evaluating the knowledge and attitude of fathers of neonates about breastfeeding and how it influences the outcome of breastfeeding.

\section{Materials and Methods}

Setting: Teaching Hospital attached to the medical college of East Point College of Medical Sciences and Research Centre, Bangalore, Karnataka. It is a tertiary care medical facility with neonatal intensive care unit (NICU) in rural Karnataka on the outskirts of the state capital and IT hub Bangalore.

Duration and Period: Three months between April 2019 and June 2019

Study: This is a prospective cohort study. This is a questionnaire-based study, conducted on a pilot study basis using a self-developed questionnaire.

Inclusion criteria: All fathers of consecutive live neonates born in our hospital, within 72 hours of life of the newborn.

Exclusion criteria: 1. Still birth, IUD. 2. Fathers not available within 72 hours of birth. 3. Out born neonates admitted to our hospital. 3. Consent not given.

Data collection procedure: The study questionnaire was with 2 parts. The first part consists of questions related to basic information and second part related to breast feeding. The fathers of neonates born inborn within 72 hours of life, were given the questionnaire and the response was evaluated.

Data analysis: Data were entered in MS - excel workbook sheet and was analysed using MS- Excel software. The institutional ethical committee approval was obtained and consent was taken from fathers before participating in the study.

\section{Results}

A total of 104 fathers were included in the study $(n=104)$.

Father - Age (Av) 28.8 years, most were literate, having completed high school. Neonates- M: F ratio was 1.2:1, 75\% born at term, $40 \%$ first born (Table 1 ).

All fathers agreed that breast feeding is essential. 78 out of 104(75\%) said yes to 6 months duration for exclusive breast feeding. However, it seems most father's consider plain water and bottle formula feeds not contravening this recommendation of WHO. 59 out of $104(60 \%)$ felt plain water should be given while breast feeding and about $47 \%$ felt it is good to give bottle formula feeds.

It is important to note that another 45\% (46 out of 104) disagreed that bottle formula feeds are good. 92 out of 104 (90\%) agreed breast feeding is a cheaper option than formula feeds.

Surprisingly, only 12 out of 104 (11\%) reported any difficulty in breast feeding while 72 (70\%) responded no and 20 (19\%) ticked don't know/ can't say. This response in the early neonatal periods when most nursing mothers report difficulties may indicate the lack of interaction with the new mother minimal involvement of the father in newborn care.

Only about $30 \%$ had attended antenatal counselling regarding breast feeding though nearly $70 \%$ felt fathers have a supporting role in breast feeding. Less than $10 \%$ father's felt they have no role in breast feeding. (Table 2)

Pediatric Review: International Journal of Pediatric Research Available online at: www.medresearch.in 455|P a g e 


\section{Original Research Article}

Table-1: Basic Information.

\begin{tabular}{|c|c|c|}
\hline Basic information & & \\
\hline \multirow[t]{5}{*}{ Father age } & & \\
\hline & $20-25$ & $15(14 \%)$ \\
\hline & $26-30$ & $52(51 \%)$ \\
\hline & $31-35$ & $22(21 \%)$ \\
\hline & $>35$ & $15(14 \%)$ \\
\hline \multicolumn{3}{|l|}{ Educational status } \\
\hline & Illiterate & 11 \\
\hline & Primary & 2 \\
\hline & Middle & 11 \\
\hline & High & 49 \\
\hline & Professional & 2 \\
\hline & Graduate & 29 \\
\hline \multicolumn{3}{|l|}{ Sex } \\
\hline & Male & 57 \\
\hline & Female & 47 \\
\hline \multicolumn{3}{|l|}{ Order of gestation } \\
\hline & 1 & 41 \\
\hline & 2 & 47 \\
\hline & $>3$ & 16 \\
\hline \multicolumn{3}{|l|}{ Maturity } \\
\hline & Preterm & $23(22 \%)$ \\
\hline & Term & $76(74 \%)$ \\
\hline & Post term & $5(4 \%)$ \\
\hline \multicolumn{3}{|l|}{ Mode } \\
\hline & Normal & $26(24 \%)$ \\
\hline & Caesarean & $78(76 \%)$ \\
\hline
\end{tabular}

The responses for the 10 questions related to breast feeding were as listed in table 2 .

Table-2: Questions related to breast feeding

\begin{tabular}{|l|c|c|c|}
\hline Question & Yes & No & Don't know/ Can't say \\
\hline Essential & 104 & 0 & 0 \\
\hline 6 months EBF & 78 & 20 & 6 \\
\hline Plain water & 59 & 8 & 4 \\
\hline Beneficial-mother & 96 & 9 & 0 \\
\hline Beneficial-baby & 89 & 72 & 6 \\
\hline Difficulty & 12 & 70 & 0 \\
\hline Antenatal counselling & 34 & 46 & 10 \\
\hline Bottle formula feed & 48 & 12 & 0 \\
\hline Cheap & 92 & 11 & 26 \\
\hline Father supportive role & 67 & & 0 \\
\hline
\end{tabular}




\section{Discussion}

In spite of WHO recommendation and active promulgation regarding breastfeeding and numerous promotional initiatives, breast feeding practices leave much to be desired even in developed and advanced nations. The status in India is no better despite efforts of government and paediatricians lobbying $[3,5,7,8]$.

The father's Knowledge and Awareness of breastfeeding and its benefits to the mother and to the child has a positive effect in successful breastfeeding [9].

There is very little data available about Indian fathers' knowledge and attitude towards breastfeeding [8].

The average father in the present study was in his late 20 s, literate having completed high school. These factors do not seem to influence the overall approach of the father towards breast feeding in the present study. This is similar to findings of study in Mumbai (8) by karanda $\mathrm{S}$ et al in 2009-2010 who studied the attitude of about 250 fathers in Sion.

Abhinaya et al also in their study reported that Father's age, education status, occupation, family type had no influence on knowledge or attitude. This is in variance with international studies and findings as reported by Van Wagenen, et al 2015 and Susin, L, et al 1999 [10].

Most neonates, about $75 \%$ were born at term, $40 \%$ first born with a slight male preponderance. This distribution is in line with previous study in Chennai [10].

In the present study, majority fathers, in fact $100 \%$, were aware that breastfeeding is essential and pivotal for the baby. All previous studies confirm that majority fathers are aware that breast feeding is important and beneficial [10]. Mahesh PKB et al in their systematic review and meta-analysis published in BMC Public Health state that most fathers know the importance of breast feeding to mother and baby.

$75 \%$ agreed that exclusive breast feeding be the nutrition for the baby up to 6 months, similar to various previously conducted studies. However, it has also been reported that fathers had no role in the continuation of breast feeding from 4-6 months.

However, it seems most father's consider plain water and bottle formula feeds not contravening exclusivity.
This is an important and significant finding and is an area that needs focus and further future study. Many studies also report of using formula feeds specially in certain situations when breastfeeding might not be possible, unsuitable or inadequate $[3,4,11]$.

In fact, $60 \%$ felt plain water should be given while breast feeding and about $47 \%$ felt it is good to give bottle formula feeds along with breast feeds.

These findings show a serious gap in knowledge regarding breast feeding concepts that is adversely harming practice and the goal of WHO and paediatricians. The silver lining being that if well informed, fathers would promote exclusive breast feeding in the right way and be helpful in doing away with bottle formula feeds which is in consonance with other studies $[10,11]$. It is important to note that $45 \%$ (46 out of 104) disagreed that bottle formula feeds are good. This is a significant positive finding of the present study $[7,9,10,12]$.

Numerous studies have shown time and again that the world over many women and mother's in general endorse the notion that formula feeds are good and beneficial, at least as supplements alongside breast feeds or as a method to give exhausted and struggling mothers a "break" from their labour. More alarming is the fact that medical professionals like midwives in the UK sometimes promote this and try to hide it and avoid disclosure. The situation in our country may be no different [4, 12-17].

92 out of $104(90 \%)$ agreed breast feeding is a cheaper option than formula feeds [12]. This is overall in accordance with findings in developed and developing countries. However, studies in UK among working mothers in low income groups suggest early breastfeeding cessation so that they may get back to work [17].

Only about $11 \%$ of the respondents reported any difficulty in breast feeding, while $70 \%$ responded and $19 \%$ ticked don't know/ can't say. This is a very low rate acknowledging difficulties compared to previous studies in India or abroad [12, 18, 19].

This response in the early neonatal periods when most nursing mothers report difficulties may indicate the lack of interaction with the new mother minimal involvement of the father in new born care. 


\section{Original Research Article}

In the present study, only one third of the fathers received antenatal counselling about feeding practices. This may be because of the local socio- cultural practices where the partners are not involved in antenatal check-ups [20]. Antenatal counselling should be provided to both parents to sensitise them for exclusive breast feeding. According to American Academy of Paediatrics, the need for paternal education is stressed upon as $11^{\text {th }}$ step of successful breastfeeding.

The perceived limitations of the present study are as follows.

1. It is a cross-sectional pilot study in which around 100 fathers were included. Larger number will be needed for confirming the findings.

2. The setting of this study is a tertiary care medical facility with neonatal intensive care unit (NICU) attached to our medical college in rural Karnataka on the outskirts of the state capital and IT hub Bangalore.

3. The questionnaire is self-developed, needs further validation.Also, it was administered in the newborn period within 72 hours of birth.

4. Most fathers in the present study were literate. Majority babies were born by caesarean section, thereby the fathers likely to be having more contact with medical personnel and received counselling. Hence the fathers may have been sensitised regarding the benefits of breast feeding and been positively influenced.

\section{Conclusion}

Majority of fathers appreciate the benefits of breastfeeding in both maternal and child health. They tend to support mothers in a positive way. More awareness should be brought for exclusive breastfeeding by discouraging other feeds including water. Antenatal counselling should be done involving both the parents as the best time to counsel in the antenatal period.

This study is significant as it provides information regarding the knowledge and attitude father's viz a viz breast feeding about which very little reliable data is available in our country. It also opens up new avenues for future studies as most father's consider plain water and bottle formula feeds compatible with exclusive breast feeding. Investment in antenatal counselling for fathers may yield dividends in the form of exclusive breast feeding for mother and baby.

\section{What this study adds to the existing knowledge?}

The breast feeding can be made exclusive only with family support mainly through fathers. The focus of awareness should involve fathers to implement the same.

\section{Author's contributions}

Dr. Santosh $\mathbf{S}$ planned the study, supervised the execution and edited and approved the final manuscript as submitted for publication. Dr. Geetha $\mathbf{M}$ contributed through actual execution of the study, developed the questionnaire, critical review and appraisal of literature and drafted the manuscript. Dr. Kiran B was involved in administrative and logistical support for the study, supervised the execution and edited the manuscript.

\section{Acknowledgement:}

I thank all the participant fathers for their valuable time and interest. I thank my department colleagues for the valuable support and motivation. I thank my neonatology staff nurses for their help and support.

Funding: Nil, Conflict of interest: None initiated, Permission from IRB: Yes

\section{References}

1. Martin CR, Ling PR, Blackburn GL. Review of Infant Feeding: Key Features of Breast Milk and Infant Formula. Nutri. 2016;8(5):279.doi:10. 3390/nu8050279.

2. Mosca F, Giannì ML. Human milk: composition and health benefits. Pediatr Med Chir.2019;39(2):155. doi: 10.4081/pmc.2017.155.

3. World Health Organization. Infant and young child feeding: model chapter for textbooks for medical students and allied health professionals. Geneva: World Health Organization; 2009.

4.Habicht JP. Expert consultation on the optimal duration of exclusive breastfeeding. In Protecting Infants through Human Milk 2004 (pp.79-87). Springer, Boston, MA.. doi: https://doi.org/10.1007/ 978-1-4757$4242-8 \quad 8$

5. Hansen E, Tesch L, Ayton J. 'They're born to get breastfed'- how fathers view breastfeeding: a mixed method study. BMC Pregnancy Childbirth. 2018;18(1): 238. doi: 10.1186/s12884-018-1827-9. 


\section{Original Research Article}

6. Sherriff, N., Panton, C. and Hall, V. (2014) A New Model of Father Support to Promote Breastfeeding. Community Pract. 87(5):20-24.

7. Pontes CM, Osório MM, Alexandrino AC. Building a place for the father as an ally for breast feeding. Midwifery. 2009; 25(2):195-202. doi: https://doi.org/10. 1016/j. midw.2006.09.004

8. Dick JA, Dennis CL. Breast-feeding Co-parenting framework. Fam Community Health. 2017;40(1):28-31. doi: 10.1097/FCH.0000000000000137.

9.Abhinaya K, Arunprasath TS, Padmasani LN. Father's knowledge and attitude towards breast feeding. Int J Med Res Rev 2016;4(10): 1778-1785.doi:10. 17511 / ijmrr. 2016.i10.12.

10. Chandhiok N, Singh Kh J, Sahu D, Singh L, Pandey A. Changes in exclusive breastfeeding practices and its determinants in India, 1992-2006: analysis of national survey data. Int Breastfeed J. 2015; 10:34. doi: 10 . 1186/s13006-015-0059-0. eCollection 2015.

11. Dutta S, Singh B, Chessell L, Wilson J, Janes M, Mc Donald K, Shahid S, Gardner VA, Hjartarson A, Purcha M, Watson J, De Boer C, Gaal B, Fusch C. Guidelines for Feeding Very Low Birth Weight Infants. Nutri. 2015;7(1):423-442.doi: 10.3390/nu7010423

12. Robert E, Coppieters V, Swennen B, Dramaix M. Determinants of breastfeeding in the Brussels Region. Rev Med Brux. 36(2):69-74.

13. Chaput KH, Adair CE, Nettel-Aguirre A, Musto R, Tough SC. The experience of nursing women with breastfeeding support: a qualitative inquiry. CMAJ open. 2015;3(3):E305. doi:10.9778/cmajo.20140113.
14. Cloherty, Michele et al. Supplementing breast-fed babies in the UK to protect their mothers from tiredness or distress. Midwifery, 20(2):194-204. doi: https://doi. org/10.1016/j.midw.2003.09.002

15. Furber CM, Thomson AM. The power of language: a secondary analysis of a qualitative study exploring English midwives' support of mother's baby-feeding practice. Midwifery. 2010 Apr 1; 26 (2): 232-40. doi: https: // doi. org/10. 1016/j. midw. 2008. 05. 003

16. Lakshman R, Ogilvie D, Ong KK: Mothers' experiences of bottle-feeding: a systematic review of qualitative and quantitative studies. Arch Dis Child. 2009. 94(8):596-601. 10.1136/adc.2008.151910.

17. Karande S, PerkarS. Do fathers' attitudes support breastfeeding? A cross-sectional questionnaire-based study in Mumbai, India. Indian J Med Sci 2012;66(1): 30. doi:10.4103/0019-5359.110861.

18. Mahesh PKB, Gunathunga MW, Arnold SM, et al. Effectiveness of targeting fathers for breastfeeding promotion: systematic review and meta-analysis. BMC Public Health. 2018;18(1):1140. doi:10.1186/s12889018-6037-x

19. Maycock B, Binns CW, Dhaliwal S, Tohotoa J, Hauck Y, Burns $\mathrm{S}$ et al. Education and support for fathers improves breastfeeding rates: a randomised controlled trial. J Hum Lact. 2013;29(4):484-90. doi:10. 1177/0890334413484387.

20. Bansal CP. Breastfeeding--why are we still failing? Indian Pediatr. 2013;50(11):993-934.

\section{How to cite this article?}

Santosh S, Geetha M, Kiran B. The knowledge and attitude of father in breastfeeding: a questionnaire-based study. Int J Pediatr Res.2019;6(09):454-459.doi:10.17511/ijpr.2019.109.03 